\title{
Reduction in sleep disturbances at retirement: evidence from the Swedish Longitudinal Occupational Survey of Health
}

\author{
Vera van de Straat ${ }^{1 \star}$, Loretta G. Platts ${ }^{2}$, Jussi Vahtera ${ }^{3}$, Hugo Westerlund ${ }^{2}$ and Piet Bracke ${ }^{1}$ \\ ${ }^{1}$ Health and Demographic Research, Department of Sociology, Ghent University, Ghent, Belgium, ${ }^{2}$ Stress \\ Research Institute, Stockholm University, Stockholm, Sweden and ${ }^{3}$ Department of Public Health, \\ University of Turku and Turku University Hospital, Turku, Finland \\ ${ }^{*}$ Corresponding author. Email: Vera.vandeStraat@UGent.be
}

(Accepted 3 April 2019; first published online 15 May 2019)

\begin{abstract}
Although retirement involves a radical change in daily activities, income, social roles and relationships, and the transition from paid work into retirement can, therefore, be expected to affect sleep, little is known about the effects of old-age retirement on changes in sleep disturbances, and how the impact of retirement may vary by gender, age and prior working conditions. This study modelled reported sleep disturbances up to nine years before to nine years following retirement in a sample of 2,110 participants from the Swedish Longitudinal Occupational Survey of Health (SLOSH). Sleep disturbances over the retirement transition were modelled using repeated-measures regression analysis with Generalized Estimating Equations (GEE) in relation to gender, age at retirement, working patterns (night work, full-time/part-time work), control over work hours, and psychological and physical working conditions. The analyses controlled for civil status, education level, income obtained from registers and self-rated health. Retiring from paid work was associated with decreased sleep disturbances. Greater reductions in sleep disturbances were reported by women, as well as by participants who retired before age 65 years, who were working full-time, who lacked control over their work hours and who had high psychological demands. These results, suggesting that old-age retirement from paid work is associated with reductions in disturbed sleep, pose a challenge for governments seeking to increase retirement ages.
\end{abstract}

Keywords: work-time control; gender; retirement; sleep disturbances; psychological work demands; physical work demands

\section{Introduction}

Adults generally spend one-third of their time at work and another third asleep. In early old age this typical daily schedule alters due to the transition from paid work into retirement (Eibich, 2015). Besides altering daily activities, retirement also changes people's level of income and affects their social roles and relationships 
(Pinquart and Schindler, 2007). Such radical changes in people's daily lives can also be expected to affect their sleep. Nevertheless, few studies have examined the effects of retirement on sleep. Cross-sectional studies comparing retirees with those still in paid work found that retirees sleep longer (Webb and Aber, 1985; Hale, 2005), but also report a higher prevalence of sleeping problems (Ito et al., 2000; van de Straat and Bracke, 2015). However, such single time-point studies comparing retirees with those in paid work are vulnerable to selection effects in which healthier people are more likely to stay in paid work and less likely to retire. Researchers aiming to determine whether the retirement transition causes a change in sleep are consequently turning to more robust, longitudinal designs which follow individuals out of paid work into retirement. Results from such repeated-measures designs indicate that sleeping problems are common during the final working years and sleep improves following retirement, whether in terms of longer sleep duration (Eibich, 2015; Hagen et al., 2016; Myllyntausta et al., 2017) or better sleep quality (Marquié and Foret, 1999; Vahtera et al., 2009; Myllyntausta et al., 2018), especially reduced premature awakening and non-restorative sleep (Marquié et al., 2012; Myllyntausta et al., 2018).

Several mechanisms have been suggested for such improvements in sleep at retirement. An important mechanism may be reduced pressure to sleep at fixed times that accompanies the transition from work to retirement (Marquié et al., 2012). Another mechanism inhibiting sleep may be work stress generating worry or hyper-arousal. Since previous studies have observed strong positive associations between work stress and sleep disturbances (Ota et al., 2005; Knudsen et al., 2007; Halonen et al., 2017) and a greater reduction of sleep difficulties at retirement for those with high work stress (Vahtera et al., 2009; Myllyntausta et al., 2018), improvement in sleep at retirement could be related to the removal of exposures to adverse psycho-social working conditions.

In this study, a repeated-measures design will be used to observe whether retirement is associated with a reduction in sleep disturbances amongst Swedish retirees by following them from up to nine years before until nine years following retirement. Since examining differences between groups in how their sleep is affected by retirement may be a way to reveal the mechanisms underlying the previously observed improvements in sleep after retirement, this study will examine how the association varies by gender, retirement age, working patterns, control over work hours, and psychological and physical work demands. It will focus on two mechanisms in particular: reduced pressure to sleep at fixed times (to be tested by examining change in sleep disturbances at retirement in different groups according to their night work, full-time work and their level of work-time control) and the impact of relief from work stress.

\section{Retirement and sleep}

Williams (2003) describes sleep as socially scheduled, managed and prepared for. In order to schedule sleep effectively, the activities that affect the ability to sleep need to be regulated (Schwartz, 1970). Since the working population generally spends as much time at work as asleep, scheduling of sleep is largely dependent on the organisation of paid work (Tucker et al., 2016; Schiller et al., 2018). Indeed, paid work is 
reported to be the activity that is most often exchanged for sleep (Basner et al., 2014). Work stress, in terms of a poor psycho-social work environment and stressful experiences at work, which leaves people feeling bothered or upset, is associated with the development of sleeping problems and poor sleep quality (Linton, 2004; Burgard and Ailshire, 2009; Magnusson Hanson et al., 2014; Åkerstedt et al., 2015). Using repeat data, onset of job strain was found to increase the risk of subsequent onset of insomnia symptoms in participants, while disappearance of job strain reduced the risk of future insomnia symptoms among those with sleeping problems (Halonen et al., 2017). However, there is also some evidence that sleep disturbances could lead to higher perceived work stress (Magnusson Hanson et al., 2011), but also to more severe consequences of work stress in terms of depressive symptoms (Magnusson Hanson et al., 2017). Nevertheless, a strong increase in work-related sleep disturbances was found in the Swedish working population between 1993 and 1999 (Westerlund et al., 2008), and longitudinal studies from occupational cohorts in France and Finland have reported declines in sleeping problems at retirement (Vahtera et al., 2009; Myllyntausta et al., 2018). Consequently, we expect the retirement transition to be associated with a decrease in the experience of sleep disturbances (Hypothesis 1).

\section{Gender, retirement and sleep}

Prior research suggests that post-retirement changes in sleep may depend on gender. A study based on a French cohort found a larger post-retirement improvement in sleep for men than for women (Vahtera et al., 2009). However, no gender difference in sleep changes around retirement was observed in a large Finnish publicsector cohort (Myllyntausta et al., 2018). Similarly, research into wellbeing has described transitions from work to retirement as being more important for the psychological wellbeing of men than of women (Kim and Moen, 2002). In men, the benefit of retirement was explained by the release from work-related pressure and an increase in general life satisfaction. Furthermore, men are more likely to be in paid work full-time at retirement (Ruhm, 1996), making the change in daily schedules bigger for men than for women. Another potential explanation is that women are exposed to longer unpaid working hours than men, such as by performing care-giving or housework (MacDonald et al., 2005), which means that women may experience a smaller relative decline in total working hours (paid and unpaid work) at retirement from full-time paid work than men. Based on these findings, we hypothesise the decrease in the experience of sleeping problems after retirement to be stronger for men than for women (Hypothesis 2).

\section{Age at retirement and sleep}

Previous research has suggested that age at retirement modifies the association between retirement transition and sleep. However, these findings have been inconsistent, with both theoretical arguments and empirical evidence pointing in different directions. Vahtera et al. (2009) found a more pronounced reduction in sleep disturbances after retirement for people who retired at an older age than for those who retired at a younger age. This may be because older people are more 
vulnerable to sleeping problems, and therefore there is a stronger association between paid work and sleeping problems at older ages. In contrast, Hagen et al. (2016) observed smaller increases in sleep duration and lesser wake time extensions among people who retired at older ages and Myllyntausta et al. found similar improvements in sleep quality (Myllyntausta et al., 2018) and quantity (Myllyntausta et al., 2017) at retirement in all age groups. The inconsistencies between the different studies may partly be explained by the relatively young respondents included in the study by Vahtera et al. (2009), where the retirement age varies between 37 and 62 years with an average retirement age of 54 years, whereas the average age at retirement is much closer to the mid-sixties in the other studies. It is possible that the changing social roles at retirement may have less of an impact on sleep duration and sleep timing for people who retire at an older age, because age-related decreases in sleep quality may limit the possibility for sleep to improve once the stressors associated with paid work are removed (Hagen et al., 2016). Another possibility is health selection into retirement since those more vulnerable to sleeping problems and their consequences are likely to choose earlier retirement than good sleepers, which means that the population of old workers contains a higher proportion of people who are already having sleeping patterns that are close to their natural pattern. Therefore, we expect the association between the retirement transition and sleep disturbances to be less strong for older retirees (Hypothesis 3).

\section{Work hours, retirement and sleep}

At retirement a person's daily schedule may change (Eibich, 2015), because the loss of work-related responsibilities may reduce the pressure to sleep at fixed times. This is likely to increase individuals' control over their sleeping context (Arber et al., 2007), impacting on how people schedule, manage and prepare for their sleep (Marquié et al., 2012). In this vein, Hagen et al. (2016) found that the transition from work to retirement was associated with later bedtimes and wake times, as well as longer sleep duration, results which suggest that the constraints of paid work had forced people into sleeping patterns that were different from their natural ones.

Since night work is the best example of forcing people into sleep patterns that are different from their natural ones, we expect individuals who work night shifts to experience a bigger improvement in sleep after retirement than those who work during the day (Hypothesis 4a). Additionally, people working more hours can be expected to be more likely to replace sleep by work than people who work less. Therefore, the sleep of people retiring from full-time paid work can be expected to improve more than the sleep of people retiring from part-time work (Hypothesis 4b). A third aspect that deals with the timing of work is work-time control. Following previous researchers (e.g. Knauth, 1998; Härmä, 2006; Tucker et al., 2016), work-time control is defined as an employee's influence on the distribution, position and duration of his or her work time. Higher levels of work-time control have been found to be associated with better sleep (Kubo et al., 2013; Salo et al., 2014). One of the suggested underlying mechanisms is that having greater work-time control enables an individual to adjust their work hours to their natural sleep pattern to a greater degree (Baltes et al., 1999; Tucker et al., 2016). Because 
individuals with greater work-time control may have a sleep pattern that is closer to their natural pattern, we expect people with greater work-time control to experience a smaller reduction in sleep disturbances at retirement than people with lower work-time control (Hypothesis 4c).

\section{Psychological work demands, physical occupational exposures and sleep}

Previous research has reported associations between occupational stress and sleep disturbances (Åkerstedt et al., 2002; Halonen et al., 2017) and improvements in sleep difficulties for those retiring from work with high job demands (Vahtera et al., 2009) and job strain (Myllyntausta et al., 2018). Reductions in sleeping problems at retirement may be due to the removal of worry and hyper-arousal related to work stress. Physically strenuous work has also been associated with sleep disturbances (Ribet and Derriennic, 1999; Åkerstedt et al., 2002), consequently, removal of this physical stressor may be associated with improved sleep in retirement. Therefore, we hypothesise that people with greater psychological work demands and physical occupational exposures will experience greater reductions in sleep disturbances at retirement (Hypothesis 5).

\section{Data and methods}

\section{Data}

The data were drawn from the 2006, 2008, 2010, 2012, 2014 and 2016 waves of the Swedish Longitudinal Occupational Survey of Health (SLOSH). SLOSH (total N = 40,877 ) is a biennial follow-up study of respondents from the Swedish Work Environment Survey 2003-2011, which means that it is originally nationally representative of the Swedish working population aged 16-64 years. Data are collected by postal questionnaires and are linked to administrative register data. There are two versions of the survey: participants are provided with written instructions to fill in one version if they are in paid work for at least 30 per cent of full-time and to fill in the other version if they are in paid work less than 30 per cent or are outside the labour force, e.g. if they are unemployed or retired. SLOSH was set up in order to investigate the associations between aspects of working life and people's health over time.

For this study, the sample was limited to those individuals who responded to the survey in at least one wave before and one wave after their retirement. From the total sample, 2,110 individuals were identified who were employed in at least one wave and who, in the following wave, reported being in old-age retirement and filled in the non-worker questionnaire. Respondents who were employed but had been sick listed before retirement and those who retired with disability pension were excluded. On average, participants provided data in 4.4 (range 2-6) of the possible six waves of data collection.

\section{Assessment of retirement}

Data on year of retirement were obtained from the questionnaire data. The year between the last worker questionnaire and the wave the respondent reported to 
Table 1. Data structure

\begin{tabular}{|c|c|c|c|c|c|c|c|c|c|c|c|}
\hline & \multicolumn{11}{|c|}{ Years in relation to retirement $(R)$} \\
\hline & -9 & -7 & -5 & -3 & -1 & $\mathrm{R}$ & +1 & +3 & +5 & +7 & +9 \\
\hline \multirow[t]{5}{*}{ Data collection years } & & & & & 2006 & & 2008 & 2010 & 2012 & 2014 & 2016 \\
\hline & & & & 2006 & 2008 & & 2010 & 2012 & 2014 & 2016 & \\
\hline & & & 2006 & 2008 & 2010 & & 2012 & 2014 & 2016 & & \\
\hline & & 2006 & 2008 & 2010 & 2012 & & 2014 & 2016 & & & \\
\hline & 2006 & 2008 & 2010 & 2012 & 2014 & & 2016 & & & & \\
\hline $\mathrm{N}$ & 145 & 501 & 861 & 1,202 & 2,076 & & 2,086 & 1,117 & 755 & 389 & 110 \\
\hline
\end{tabular}

Note: $\mathrm{N}=2,110$.

Source: Swedish Longitudinal Occupational Survey of Health.

be retired full-time was assigned as the year of retirement. The normative retirement age for men and women in Sweden is 65 years, but it is possible for people to retire, whether part-time or full-time, and receive pensions at younger and older ages, generally between 61 and 67 years (Stattin and Larsson, 2015). For analytical purposes, the year of retirement was set to 0 and the time relative to retirement was measured in the number of years before and after retirement. Since there is a twoyear period between each survey wave, this variable ranges from nine years before until nine years after retirement (Table 1). Beside this time variable, a retirement period variable was created that distinguishes between the pre-retirement period containing the years -9 to -3 , the retirement transition years -1 to +1 , and the post-retirement period years +3 to +9 .

\section{Assessment of sleep disturbances}

Sleep disturbances were measured using the Karolinska Sleep Questionnaire (KSQ) with four questions regarding how often respondents had been troubled by: difficulties falling asleep, repeated awakenings with difficulties going back to sleep, premature (final) awakening and disturbed/restless sleep in the last three months (Magnusson Hanson et al., 2011; Nordin et al., 2013). For these questions, the response categories varied from never, rarely/occasionally, sometimes/a few times a month, often/one or two times a week, most of the time/three or four times a week to always/five times a week or more. Mean scores for the KSQ disturbed sleep scale were calculated, with higher scores indicating higher levels of disturbed sleep. The Cronbach's $\alpha$ for the disturbed sleep scale varied between 0.83 and 0.85 in the different waves. For each respondent we used all available measurements.

\section{Assessment of work characteristics}

Aspects of working conditions that could affect the association between retirement and sleep disturbances were included in the analyses. All variables were measured in the last wave prior to retirement. First, respondents were asked whether or not 
they were performing night work. Second, work hours were taken into account based on a question asking whether the respondent is employed on a full- or parttime basis. Those who responded that they are working full-time were separated from those working part-time. Individuals with varying work hours and a small minority of participants without contracted hours (e.g. farmers) were combined and categorised as working varying hours.

Following Tucker et al. (2016), work-time control was measured using a six-item scale that includes perceived influence over the length of the work day, starting and ending times of a work day, taking of breaks during the work day, scheduling of work days, scheduling of vacations and paid days off, and the ability to run private errands during the work day. The level of work-time control was rated on a five-point Likert scale ranging from very little to very much. The Cronbach's $\alpha$ varied between 0.87 and 0.89 in the different waves. This variable was dichotomised, categorising those with a mean score varying from 0 to 1 as having little control over working hours and those with a higher score as having high control over working hours. In cases of missing values in the year before retirement, the most recent available data were used.

Psychological work demands consisted of a mean score of five items inquiring after: having to work fast, having to work intensively, work demanding too much effort, work involving conflicting demands and having enough time (reverse coded) (Knudsen et al., 2007). The four response options ranged from never to often. The Cronbach's $\alpha$ for psychological work demands varied between 0.72 and 0.75 in the different waves. The score was dichotomised: response scores lower than 2 were categorised as having no/low psychological work demands, scores of 2 and higher meant high psychological work demands. The mean score for physical occupational exposures was calculated for the following six items which measure exposure to physical hazards and strenuous job tasks: exposure to disturbing or tiresome noise; poor or excessively bright light; vibrations that make the whole body shake and vibrate; toxins or irritants; excessive heat, cold or draught, and tangible risk of injury. Response categories ranged from: no, not at all, a little, about 25 per cent of the time, about half the time, about 75 per cent of the time to almost all the time. In the different waves the Cronbach's $\alpha$ for this scale varied between 0.77 and 0.80 . The score was dichotomised by categorising scores lower than 2 as no/low physical occupational exposures and scores of 2 and higher as having high physical occupational exposures before retirement.

\section{Assessment of covariates}

Gender and age at retirement were also included. Age at retirement was calculated by comparing respondents' birth and retirement years and was then categorised into the following three categories: retired before the age of 65 , retired at the age of 65 and retired after the age of 65 .

The analyses were further controlled for civil status, education, income and selfrated health, all measured in the last wave before retirement. Civil status, education and income were retrieved from the social security and tax register databases. Civil status was divided into two categories: married versus divorced, widowed and unmarried. Education categories corresponded to the highest level of education completed: compulsory, two-year upper secondary/vocational training, three or 
four years of upper secondary education, university or equivalent for less than three years, and university or equivalent for three or more years. Annual income was measured in thousands of Swedish crowns. Self-rated health was measured on a five-point scale ranging from very poor (0) to very good (4) and dichotomised by categorising response scores $3-4$ as good health and $0-2$ as sub-optimal health.

\section{Analysis}

Data preparation was performed in IBM SPSS Statistics 22. We studied changes in sleep disturbances for up to nine years before and nine years following the retirement year, with any specific individual providing data for a minimum of three and maximum of 11 years. Repeated-measures regression analyses were performed using the Generalized Estimating Equations (GEE) method in SAS 9.4, a method which takes correlations within individuals over time into account. Additionally, rather than making the assumption that data are missing completely at random, GEE random-effects models make the less-restrictive missing at random assumption, i.e. the propensity for data to be missing is not related to the values of the missing data after accounting for relationships with observed data (Fitzmaurice et al., 2011). To illustrate the trajectory of sleep disturbances across the observation window, mean scores for sleep disturbances and their 95 per cent confidence intervals $(95 \% \mathrm{CI})$ were estimated for each time-point. To characterise how this trajectory depended on the pre-retirement characteristics of the participants, we estimated the corresponding mean scores $(95 \% \mathrm{CI}$ ) for each level of the preretirement characteristics from models including the interaction term 'time $\times$ preretirement characteristic'. Figures were created based on these estimates. Finally, we used contrasts to examine the change in sleep disturbances in three consecutive periods; the pre-retirement period (years -9 to -3 ), during the retirement transition (years -1 and +1 ) and the post-retirement period (years +3 to +9 ). Treating time as a continuous variable, we calculated the slopes divided by two years within the periods from a model including the interaction term 'time $\times$ period'. To examine how the change in the retirement transition depended on the pre-retirement characteristics of the participants, the same method was applied using interaction terms 'preretirement characteristic $\times$ time' for the period of the retirement transition. All models were controlled for gender, age at retirement, civil status, educational level, income and pre-retirement health.

\section{Results}

Characteristics of the study population in the wave before retirement are presented in Table 2 as mean values with standard deviations for continuous variables and as percentages for categorical variables. The sample consisted of 46.9 per cent men and 53.1 per cent women. Many participants in the sample $(42.6 \%)$ retired at age 65 . In the year prior to retirement, 69 per cent were married, their average annual income was 357,938 crowns (around €37,585 at 2017 rates), and 81.7 per cent were in good health. Concerning working patterns, almost 5 per cent were in night work, 60.5 per cent were in full-time employment and almost threequarters had at least some control over their work hours. 
Table 2. Descriptive statistics in the wave before retirement

\begin{tabular}{|c|c|c|}
\hline & $\mathrm{N}$ & $\%$ \\
\hline \multicolumn{3}{|l|}{ Gender: } \\
\hline Male & 990 & 46.9 \\
\hline Female & 1,120 & 53.1 \\
\hline \multicolumn{3}{|l|}{ Age at retirement: } \\
\hline$<65$ & 530 & 25.1 \\
\hline 65 & 898 & 42.6 \\
\hline$>65$ & 682 & 32.3 \\
\hline \multicolumn{3}{|l|}{ Nightwork: } \\
\hline Not working at night & 1,977 & 93.7 \\
\hline Working at night & 98 & 4.6 \\
\hline \multicolumn{3}{|l|}{ Work hours: } \\
\hline Full-time & 1,236 & 58.6 \\
\hline Part-time & 709 & 33.6 \\
\hline Varying work hours & 97 & 4.6 \\
\hline \multicolumn{3}{|l|}{ Work-time control: } \\
\hline Control over work hours & 1,405 & 66.6 \\
\hline Little control over work hours & 527 & 25.0 \\
\hline \multicolumn{3}{|l|}{ Psychological work demands: } \\
\hline No/low & 1,648 & 78.1 \\
\hline High & 204 & 21.2 \\
\hline \multicolumn{3}{|l|}{ Physical occupational exposures: } \\
\hline No/low & 1,866 & 88.4 \\
\hline High & 204 & 9.1 \\
\hline \multicolumn{3}{|l|}{ Pre-retirement health: } \\
\hline Good & 1,694 & 80.3 \\
\hline Sub-optimal & 380 & 18.0 \\
\hline \multicolumn{3}{|l|}{ Educational level: } \\
\hline Compulsory education & 483 & 22.9 \\
\hline Two-year upper secondary/vocational training & 441 & 20.9 \\
\hline Three- or four-year upper secondary & 346 & 16.4 \\
\hline University or equivalent $<3$ years & 278 & 13.2 \\
\hline University or equivalent $\geqslant 3$ years & 562 & 26.6 \\
\hline
\end{tabular}


Table 2. (Continued.)

\begin{tabular}{lcc}
\hline & $\mathrm{N}$ & $\%$ \\
\hline Civil status: & 655 & 69.0 \\
\hline Married & 1,455 & 31.0 \\
\hline Unmarried/divorced/widowed & 357.94 (166.19) \\
\hline Mean annual income prior to retirement (thousands of crowns) (SD)
\end{tabular}

Notes: $\mathrm{N}=2,110$. SD: standard deviation.

Source: Swedish Longitudinal Occupational Survey of Health.

Reported sleep disturbances at the wave preceding retirement was higher for participants who were female, who retired at an older age, had little control over work hours and reported higher psychological work demands (Table 3). Night working and physical occupational exposures were not associated with sleep disturbances at the wave preceding retirement. Work hours were only associated with sleep disturbances at the 10 per cent significance level.

\section{Changes in sleep disturbances around retirement}

We hypothesised that the retirement transition would be associated with a decrease in subjective sleep disturbances (Hypothesis 1). Figure 1 shows the mean score for sleep disturbances across the observation window. There is a small increase in sleep disturbances over the years leading up to retirement, a major decrease in sleep disturbances during the retirement transition and, despite a small increase in sleep disturbances following retirement, lower levels of sleep disturbances in the period following retirement. Although Figure 1 suggests small increases in the pre- and post-retirement periods, the estimates of the slopes showed that only the pre-retirement increase (0.04; $95 \% \mathrm{CI}=0.01,0.07)$ and the decrease in sleep disturbances during the retirement transition $(-0.21 ; 95 \% \mathrm{CI}=-0.25,-0.17)$ were significantly different from zero.

\section{Changes in sleep disturbances at retirement in relation to individuals' characteristics}

We hypothesised that improvements in sleep disturbances might vary by gender; age at retirement; working patterns, specifically, night shifts, work hours (full-time, part-time, varying) and work-time control; and by levels of psychological demands and physical occupational exposures. To test whether change in sleep disturbances during the transition to retirement differed according to each of these covariates, interaction effects were estimated. Based on a two-way interaction between each variable of interest and time, the slopes for the retirement transition for each group are presented in Table 3. The models are adjusted for gender, age at retirement, civil status, educational level, income and pre-retirement health. The trajectories are visualised in Figure 2.

As Table 3 shows, significant differences in the trajectories were found for gender $(p<0.001)$, age at retirement $(p<0.001)$, work hours $(p=0.019)$, work-time control $(p=0.035)$ and psychological work demands $(p<0.001)$. The mean 
Table 3. Mean sleep disturbance in the wave before retirement and the change in sleep disturbance during the transition into retirement

\begin{tabular}{|c|c|c|c|c|c|}
\hline & \multicolumn{2}{|c|}{$\begin{array}{l}\text { Pre-retirement period } \\
\text { wave before retirement }\end{array}$} & \multicolumn{2}{|c|}{ Retirement transition } & \multirow{2}{*}{$\begin{array}{c}p \text { for } \\
\text { interaction } \\
\text { with time }\end{array}$} \\
\hline & $\begin{array}{l}\text { Mean sleep } \\
\text { disturbance }\end{array}$ & $95 \% \mathrm{Cl}$ & Slope & $95 \% \mathrm{Cl}$ & \\
\hline Gender: & & & & & $<0.001$ \\
\hline Male & 1.35 & $1.29,1.42$ & -0.13 & $-0.18,-0.08$ & \\
\hline Female & 1.77 & $1.70,1.83$ & -0.28 & $-0.33,-0.23$ & \\
\hline Age at retirement: & & & & & $<0.001$ \\
\hline$<65$ & 1.46 & $1.39,1.53$ & -0.39 & $-0.47,-0.32$ & \\
\hline 65 & 1.56 & $1.49,1.62$ & -0.20 & $-0.26,-0.15$ & \\
\hline$>65$ & 1.75 & $1.66,1.84$ & -0.08 & $-0.14,-0.02$ & \\
\hline Night work: & & & & & 0.738 \\
\hline Not working at night & 1.58 & $1.53,1.62$ & -0.24 & $-0.41,-0.07$ & \\
\hline Working at night & 1.56 & $1.34,1.78$ & -0.21 & $-0.25,-0.17$ & \\
\hline Work hours: & & & & & 0.019 \\
\hline Full-time & 1.53 & $1.47,1.59$ & -0.25 & $-0.30,-0.21$ & \\
\hline Part-time & 1.65 & $1.57,1.72$ & -0.17 & $-0.23,-0.10$ & \\
\hline Varying work hours & 1.57 & $1.38,1.76$ & -0.10 & $-0.22,0.03$ & \\
\hline Work-time control: & & & & & 0.035 \\
\hline $\begin{array}{l}\text { Control over work } \\
\text { hours }\end{array}$ & 1.53 & $1.47,1.58$ & -0.18 & $-0.22,-0.14$ & \\
\hline $\begin{array}{l}\text { Little control over work } \\
\text { hours }\end{array}$ & 1.71 & $1.62,1.80$ & -0.28 & $-0.36,-0.20$ & \\
\hline $\begin{array}{l}\text { Psychological work } \\
\text { demands: }\end{array}$ & & & & & $<0.001$ \\
\hline No/low & 1.44 & $1.39,1.49$ & -0.14 & $-0.18,-0.10$ & \\
\hline High & 2.06 & $1.95,2.16$ & -0.48 & $-0.57,-0.39$ & \\
\hline $\begin{array}{l}\text { Physical occupational } \\
\text { exposures: }\end{array}$ & & & & & 0.394 \\
\hline No/low & 1.56 & $1.51,1.61$ & -0.22 & $-0.25,-0.18$ & \\
\hline High & 1.62 & $1.48,1.77$ & -0.15 & $-0.29,-0.02$ & \\
\hline
\end{tabular}

Notes: $\mathrm{N}=2,110 . \mathrm{Cl}$ : confidence interval. Models are adjusted for gender, age at retirement, civil status, educational level, income and pre-retirement health.

Source: Swedish Longitudinal Occupational Survey of Health.

decrease in sleep disturbances during the retirement transition was stronger for women $(-0.28)$ than for men $(-0.13)$. As hypothesised, a smaller decrease in sleep disturbances at retirement occurred for participants who retired after age $65(-0.08)$ than for those who retired at $65(-0.20)$. It is also possible to observe 


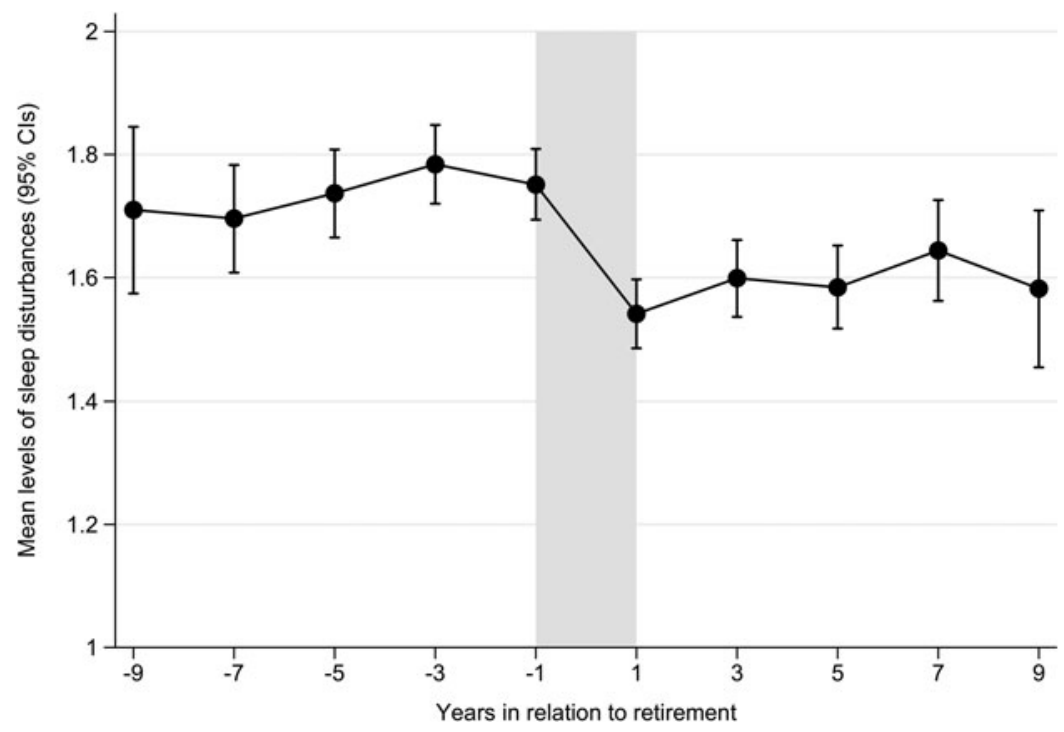

Figure 1. Mean scores of sleep disturbances (0-5) and $95 \%$ confidence intervals by wave relative to retirement $(0=$ year of retirement), adjusted for gender, age at retirement, civil status, educational level, income and preretirement health. Swedish Longitudinal Occupational Survey of Health, $N=2,110$. Note: Cls: confidence intervals.

that those who retired before age $65(-0.39)$ had a larger decrease in sleep disturbances than those retiring at age 65 .

The degree of reduction in sleep disturbances did not differ significantly at the 95 per cent level between participants performing night work and those not performing night work, leading to Hypothesis 4a not being confirmed. Different trajectories were found for the different groups of both work hours and work-time control. The decrease in sleep disturbances in the retirement transition seemed to be stronger for people working full-time than for people working part-time and people with varying work hours, which supports Hypothesis 4b. Hypothesis $4 \mathrm{c}$ is also supported by a larger reduction in sleep disturbances at retirement for people who lacked work-time control $(-0.28)$ compared to those who had control over their working hours $(-0.18)$.

Finally, people with higher psychological work demands and physical occupational exposures were hypothesised to experience a greater reduction in sleep disturbances at retirement (Hypothesis 5). Retirement was associated with a greater reduction in sleep disturbances for participants with higher psychological work demands $(-0.48)$ compared to those with no or low psychological work demands $(-0.14)$, but significantly different trajectories were not found in relation to physical occupational exposures $(p=0.394)$.

\section{Discussion}

This paper uses repeated measures to present longitudinal trends in sleep disturbances in relation to retirement in a sample drawn from the Swedish working 

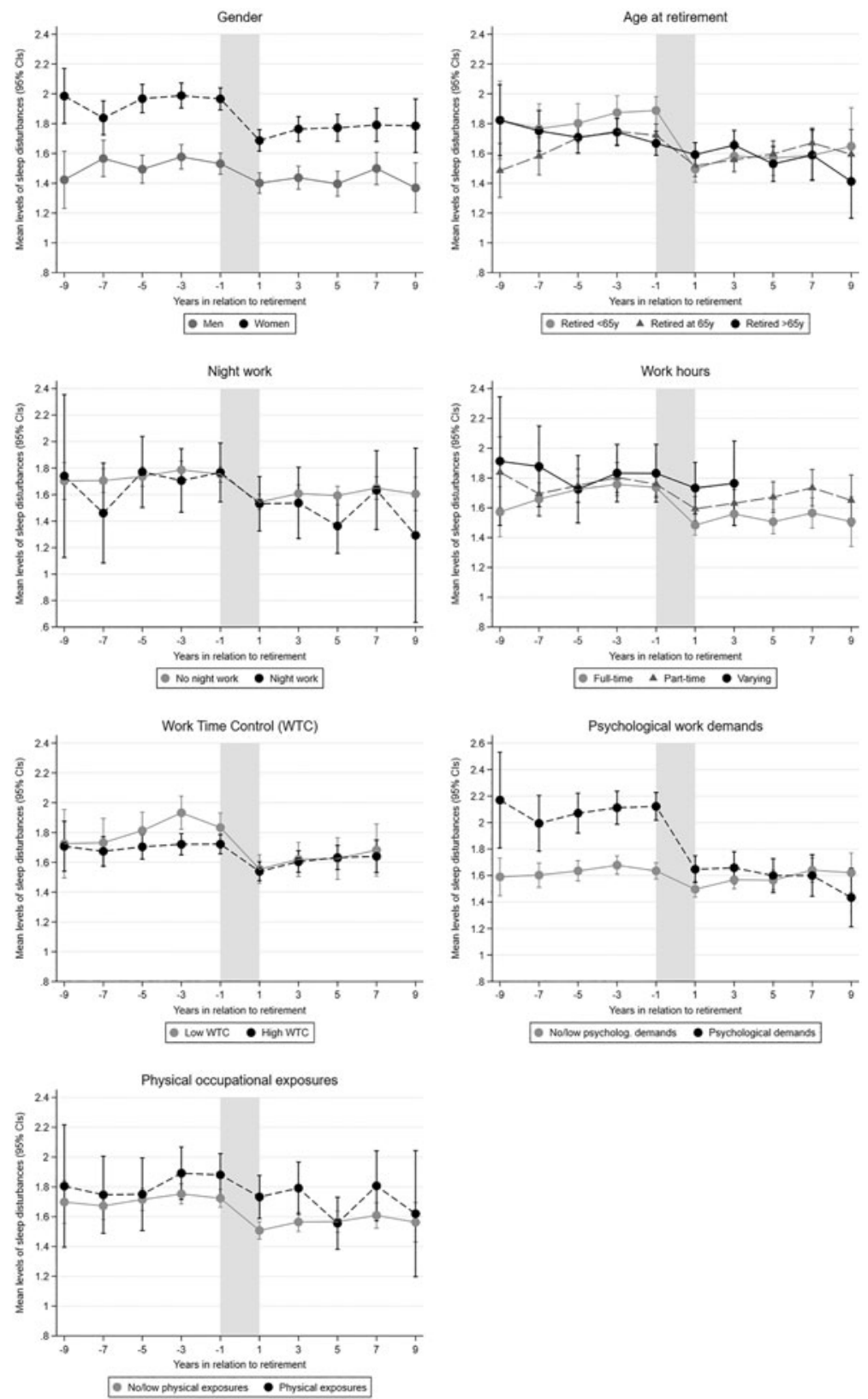

Figure 2. Mean scores of sleep disturbances (0-5) relative to retirement by gender, age at retirement, night work, work hours, work time control, psychological work demands and physical occupational exposures. Estimates with 95\% confidence intervals adjusted for gender, age at retirement, civil status, educational level, income and preretirement health. Swedish Longitudinal Occupational Survey of Health, N $=2,110$.

Notes: Cls: confidence intervals. WTC: work-time control. 
population, followed up from up to nine years before to up to nine years following retirement. In order to examine likely mechanisms underlying the association between the retirement transition and sleep disturbances, differences between groups according to their demographic and pre-retirement characteristics were examined.

Retiring from paid work was associated with a decrease in reported sleep disturbances, a finding which reproduces earlier results from Vahtera et al. (2009) on the beneficial impact of retirement on sleep in the French GAZEL cohort of workers from gas and nuclear industries, as well as Myllyntausta et al. (2018), who also find reductions in sleep difficulties in a Finnish public-sector cohort. The current study extends these findings to a different country context, and to the general working population, as compared to the specific job sectors that Vahtera et al. (2009) and Myllyntausta et al. (2018) studied.

In order to shed light on potential mechanisms, variations in the retirementsleep disturbances associations by group were examined. The decrease in sleep disturbances at retirement was significantly stronger for women than for men, which is in contrast with Hypothesis 2, which anticipated larger improvements for men, as previously found by Vahtera et al. (2009). It also contrasts with a previous finding by Myllyntausta et al. (2018), who did not find a gender difference. Since previous studies have found strong positive associations between work-family conflict and sleep complaints (Sekine et al., 2006; Nylén et al., 2007; Lallukka et al., 2010; Crain et al., 2014), the disappearance of work-family conflicts at retirement may explain the sharper decline in sleep disturbances at retirement among women.

Age at retirement also altered the trajectory of reduction in sleep disturbances at retirement. Participants who retired before age 65 had higher pre-retirement levels of sleep disturbances compared to those retiring at 65 or after 65 years, as well as the strongest decrease in sleep disturbances at retirement. The pre-retirement level of sleep disturbances for those who retired after the age of 65 was lower and barely changed during the transition period. These findings are in line with the possibility that age-related decreases in sleep quality limit the possibility for sleep to improve once the stressors associated with paid work are removed (Hagen et al., 2016). They also correspond to the possibility of health selection into retirement generating a group of older workers who already have sleeping patterns that are close to their natural pattern, and which changes little if at all following retirement.

A previously suggested mechanism behind the association between retirement and reduced sleep disturbances is that the retirement transition reduces the pressure to sleep at fixed times (Marquié et al., 2012; Hagen et al., 2016). In order to test this mechanism, the retirees were divided into different groups according to whether they worked during the night, worked full-time and their level of work-time control. Trajectories did not differ according to whether individuals participated in night work, a result which confirms the recent finding of Myllyntausta et al. (2018). The differences in relation to degree of work-time control and number of work hours suggest that participants who could schedule their work hours more flexibly benefited less from retirement than those who had little control over their work hours and that participants who worked fewer hours (part-time or varying hours) benefited less from retiring than those who worked full-time. Although we did not find differences in the trajectories based on night work, based on the 
findings for work-time control and work hours, we conclude that the mechanism of reduced pressure to sleep at fixed times may be able to explain to some degree the decrease in the experience of sleep disturbances at retirement in our sample.

Another potential mechanism which might explain reduced sleep disturbances following retirement is the removal of worry and hyper-arousal related to work stress. Our study is the first to demonstrate a relationship between work stress and reductions in sleep disturbances at retirement in a sample drawn from the general working population, rather than working in specific sectors and benefiting from relatively generous pension schemes. The corroboration provided by these three studies together in a variety of European settings offers a generalisable picture in which job stress appears to be causing sleep disturbances, a finding with important policy implications.

The lack of differences in the association between retirement and sleep disturbances by the level of physical occupational exposures might be explained by the fact that one important mechanism may be musculoskeletal pain, which may persist beyond or even begin following retirement (Descatha et al., 2012; Plouvier et al., 2015), or that the tiring physical effort of physically active jobs may increase the need for sleep, causing in-work participants to report less disturbed sleep than would otherwise be the case.

\section{Strengths and limitations}

The study's strengths include the lengthy period of time under study during which repeated measures of sleep disturbances and the covariates were available, which enables long trajectories of sleep disturbances during retirement to be examined. This study extends the results on the beneficial impact of retirement on sleep found in two occupational cohorts (Vahtera et al., 2009; Myllyntausta et al., 2018) to a large sample of the general working population in Sweden. This extends the results not only from specific sectors with financial security in retirement to the general working population, but also to a different national context. Sleep disturbances were measured using a validated four-item scale from the KSQ, which has good measurement properties (Magnusson Hanson et al., 2011; Nordin et al., 2013).

However, there are certain limitations. The models are only adjusted for a limited set of covariates (gender, age at retirement, civil status, education level, income and pre-retirement health) because, although the sample is large, we believe that the study is underpowered for observing both the effects of all the covariates and the three-way interactions of time-retirement period-covariate effects in the same model. Although prior health was controlled for and participants retiring through ill-health retirement programmes were excluded, residual health selection of those with temporary sleeping problems into retirement may have amplified the positive effect of retirement upon sleep. However, it is most likely that such health selection does not entirely explain the results: the current study corroborates findings from Vahtera et al. (2009), in which standard retirement ages were fixed by the company, thereby excluding health selection into retirement. Furthermore, for the year of retirement, the year between the last worker questionnaire and the first year the respondent reported to be retired full-time was used. Although it can be argued that the mid-point between the waves may be the average time of retirement across 
all respondents, it is a rather imprecise measurement of retirement. The current study examines sleep disturbances using a self-reported measure; it would be valuable to carry out complementary studies on the retirement transition that use objective sleep assessments such as actigraphy before and following retirement. Since reduced pressure to sleep at fixed times may be an important mechanism that accompanies the transition from work to retirement, it would also be relevant to include aspects such as chronotype and circadian preferences to study that mechanism in future studies.

\section{Conclusions}

This study found that retirement from paid work was associated with reduced sleep disturbances in a sample drawn from the general Swedish working population. Sleep disturbances decreased by more at retirement for women and for workers who retired before the normative retirement age of 65 years; however, aspects of work scheduling did not moderate the reduction in sleep disturbances, except for control over work hours. These results are relevant in the light of the efforts of governments in many advanced economies to raise effective retirement ages. Since sleep disturbances are relatively common in older people (Asplund, 1999; Vitiello et al., 2004; Metlaine et al., 2005; Fok et al., 2010), raising statutory retirement ages may worsen sleeping problems in this group. There are also implications for inequalities: as those who retired before the normative age of 65 years experienced the largest reductions in sleep disturbances, increasing effective retirement ages may adversely affect the sleep of such workers if they have to remain in paid work into old age.

Author ORCIDs. (D) Vera van de Straat, 0000-0001-5043-8148; Loretta G. Platts, 0000-0002-3243-0262

Acknowledgement. Jaana Pentti developed much of the SAS script for the GEE modelling.

Author contributions. All authors approved the version to be published and made a substantial contribution to the conception and design, or analysis and interpretation of data, and the drafting of the article or revising it critically for important intellectual content.

Financial support. This work was supported by the Swedish Research Council for Health, Working Life and Welfare (LGP and VS, FORTE grant number 2012-1743). The Swedish Longitudinal Occupational Survey of Health was supported by the Swedish Council for Working Life and Social Research (FAS grant number 2005-0734) and the Swedish Research Council (VR grant numbers 2009-6192, 2013-1645). The funders had no involvement in study design, collection, analysis, interpretation of data or writing of the article.

Conflict of interest. The authors declare no conflicts of interest.

Ethical standards. The authors confirm that ethical guidelines have been met. Ethical approval for the Swedish Longitudinal Occupational Survey of Health cohort data collection was provided by the scientific secretary of the Regional Ethical Review Board in Stockholm.

\section{References}

Åkerstedt T, Garefelt J, Richter A, Westerlund H, Magnusson Hanson LL, Sverke M and Kecklund G (2015) Work and sleep - a prospective study of psychosocial work factors, physical work factors, and work scheduling. Sleep 38, 1129-1136. 
Åkerstedt T, Knutsson A, Westerholm P, Theorell T, Alfredsson L and Kecklund G (2002) Sleep disturbances, work stress and work hours: a cross-sectional study. Journal of Psychosomatic Research 53, 741-748.

Arber S, Hislop J and Williams SJ (2007) Editors' introduction: gender, sleep and the life course. Sociological Research Online 12, 1-7.

Asplund R (1999) Sleep disorders in the elderly. Drugs \& Aging 14, 91-103.

Baltes BB, Briggs TE, Huff JW, Wright JA and Neuman GA (1999) Flexible and compressed workweek schedules: a meta-analysis of their effects on work-related criteria. Journal of Applied Psychology 84, 496-513.

Basner M, Spaeth AM and Dinges DF (2014) Sociodemographic characteristics and waking activities and their role in the timing and duration of sleep. Sleep 37, 1889-1906.

Burgard SA and Ailshire JA (2009) Putting work to bed: stressful experiences on the job and sleep quality. Journal of Health and Social Behavior 50, 476-492.

Crain TL, Hammer LB, Bodner T, Kossek EE, Moen P, Lilienthal R and Buxton OM (2014) Work-family conflict, family-supportive supervisor behaviors (FSSB), and sleep outcomes. Journal of Occupational Health Psychology 19, 155-167.

Descatha A, Teysseyre D, Cyr D, Imbernon E, Chastang J-F, Plenet A, Bonenfant S, Zins M, Goldberg M, Roquelaure Y and Leclerc A (2012) Long-term effects of biomechanical exposure on severe shoulder pain in the Gazel cohort. Scandinavian Journal of Work, Environment \& Health 38, 568-576.

Eibich P (2015) Understanding the effect of retirement on health: mechanisms and heterogeneity. Journal of Health Economics 43, 1-12.

Fitzmaurice GM, Laird NM and Ware JH (2011) Applied Longitudinal Analysis. Hoboken, NJ: John Wiley \& Sons.

Fok M, Stewart R, Besset A, Ritchie K and Prince M (2010) Incidence and persistence of sleep complaints in a community older population. International Journal of Geriatric Psychiatry 25, 37-45.

Hagen EW, Barnet JH, Hale L and Peppard PE (2016) Changes in sleep duration and sleep timing associated with retirement transitions. Sleep 39, 665-673.

Hale L (2005) Who has time to sleep? Journal of Public Health 27, 205-211.

Halonen JI, Lallukka T, Pentti J, Stenholm S, Rod NH, Virtanen M, Salo P, Kivimäki M and Vahtera J (2017) Change in job strain as a predictor of change in insomnia symptoms: analyzing observational data as a non-randomized pseudo-trial. Sleep 40, zsw007.

Härmä M (2006) Workhours in relation to work stress, recovery and health. Scandinavian Journal of Work, Environment \& Health 32, 502-514.

Ito Y, Tamakoshi A, Yamaki K, Wakai K, Kawamura T, Takagi K, Hayakawa T and Ohno Y (2000) Sleep disturbance and its correlates among elderly Japanese. Archives of Gerontology and Geriatrics 30, $85-100$.

Kim JE and Moen P (2002) Retirement transitions, gender, and psychological well-being: a life-course, ecological model. The Journals of Gerontology: Series B 57, 212-22.

Knauth P (1998) Innovative worktime arrangements. Scandinavian Journal of Work, Environment \& Health 24, 13-17.

Knudsen HK, Ducharme LJ and Roman PM (2007) Job stress and poor sleep quality: data from an American sample of full-time workers. Social Science \& Medicine 64, 1997-2007.

Kubo T, Takahashi M, Togo F, Liu X, Shimazu A, Tanaka K and Takaya M (2013) Effects on employees of controlling working hours and working schedules. Occupational Medicine 63, 148-151.

Lallukka T, Rahkonen O, Lahelma E and Arber S (2010) Sleep complaints in middle-aged women and men: the contribution of working conditions and work-family conflicts. Journal of Sleep Research 19, 466-477.

Linton SJ (2004) Does work stress predict insomnia? A prospective study. British Journal of Health Psychology 9, 127-136.

MacDonald M, Phipps S and Lethbridge L (2005) Taking its toll: the influence of paid and unpaid work on women's well-being. Feminist Economics 11, 63-94.

Magnusson Hanson LL, Åkerstedt T, Näswall K, Leineweber C, Theorell T and Westerlund H (2011) Cross-lagged relationships between workplace demands, control, support, and sleep problems. Sleep 34, 1403-1410. 
Magnusson Hanson LL, Chungkham HS, Åkerstedt T and Westerlund H (2014) The role of sleep disturbances in the longitudinal relationship between psychosocial working conditions, measured by work demands and support, and depression. Sleep 37, 1977-1985.

Magnusson Hanson LL, Peristera P, Chungkham HS and Westerlund H (2017) Psychosocial work characteristics, sleep disturbances and risk of subsequent depressive symptoms: a study of time-varying effect modification. Journal of Sleep Research 26, 266-276.

Marquié J-C, Folkard S, Ansiau D and Tucker P (2012) Effects of age, gender, and retirement on perceived sleep problems: results from the VISAT combined longitudinal and cross-sectional study. Sleep 35, 1115-1121.

Marquié J-C and Foret J (1999) Sleep, age, and shiftwork experience. Journal of Sleep Research 8, 297-304.

Metlaine A, Leger D and Choudat D (2005) Socioeconomic impact of insomnia in working populations. Industrial Health 43, 11-19.

Myllyntausta S, Salo P, Kronholm E, Aalto V, Kivimaki M, Vahtera J and Stenholm S (2017) Changes in sleep duration during transition to statutory retirement: a longitudinal cohort study. Sleep 40, zsx087.

Myllyntausta S, Salo P, Kronholm E, Pentti J, Kivimaki M, Vahtera J and Stenholm S (2018) Changes in sleep difficulties during the transition to statutory retirement. Sleep 14, zsx182.

Nordin M, Åkerstedt T and Nordin S (2013) Psychometric evaluation and normative data for the Karolinska Sleep Questionnaire. Sleep and Biological Rhythms 11, 216-226.

Nylén L, Melin B and Laflamme L (2007) Interference between work and outside-work demands relative to health: unwinding possibilities among full-time and part-time employees. International Journal of Behavioral Medicine 14, 229-236.

Ota A, Masue T, Yasuda N, Tsutsumi A, Mino Y and Ohara H (2005) Association between psychosocial job characteristics and insomnia: an investigation using two relevant job stress models - the demandcontrol-support (DCS) model and the effort-reward imbalance (ERI) model. Sleep Medicine 6, 353-358.

Pinquart M and Schindler I (2007) Changes of life satisfaction in the transition to retirement: a latent-class approach. Psychology and Aging 22, 442-455.

Plouvier S, Chastang J-F, Cyr D, Bonenfant S, Descatha A, Goldberg M and Leclerc A (2015) Occupational biomechanical exposure predicts low back pain in older age among men in the Gazel Cohort. International Archives of Occupational and Environmental Health 88, 501-510.

Ribet C and Derriennic F (1999) Age, working conditions, and sleep disorders: a longitudinal analysis in the French cohort E.S.T.E.V. Sleep: Journal of Sleep Research \& Sleep Medicine 22, 491-504.

Ruhm CJ (1996) Gender differences in employment behavior during late middle age. Journals of Gerontology: Psychological Sciences and Social Sciences 51B, S11-S17.

Salo P, Ala-Mursula L, Rod NH, Tucker P, Pentti J, Kivimäki M and Vahtera J (2014) Work time control and sleep disturbances: prospective cohort study of Finnish public sector employees. Sleep 37, 12171225.

Schiller H, Lekander M, Rajaleid K, Hellgren C, Åkerstedt T, Barck-Holst P and Kecklund G (2018) Total workload and recovery in relation to worktime reduction: a randomised controlled intervention study with time-use data. Occupational and Environmental Medicine 75, 218-226.

Schwartz B (1970) Notes on the sociology of sleep. Sociological Quarterly 11, 485-499.

Sekine M, Chandola T, Martikainen P, Marmot M and Kagamimori S (2006) Work and family characteristics as determinants of socioeconomic and sex inequalities in sleep: the Japanese civil servants study. Sleep 29, 206-216.

Stattin M and Larsson D (2015) The labour market in ageing Sweden: lifecourse influences on workforce participation. In Komp K and Johansson S (eds), Population Ageing from a Lifecourse Perspective: Critical and International Approaches. Bristol, UK: Policy Press, pp. 203-220.

Tucker P, Albrecht S, Kecklund G, Beckers DGJ and Leineweber C (2016) Work time control, sleep \& accident risk: a prospective cohort study. Chronobiology International 33, 619-629.

Vahtera J, Westerlund H, Hall M, Sjösten N, Kivimäki M, Salo P, Ferrie JE, Jokela M, Pentti J, Singh-Manoux A, Goldberg M and Zins M (2009) Effect of retirement on sleep disturbances: the GAZEL prospective cohort study. Sleep 32, 1459-1466.

van de Straat V and Bracke P (2015) How well does Europe sleep? A cross-national study of sleep problems in European older adults. International Journal of Public Health 60, 643-650. 
Vitiello MV, Larsen LH and Moe KE (2004) Age-related sleep change: gender and estrogen effects on the subjective-objective sleep quality relationships of healthy, noncomplaining older men and women. Journal of Psychosomatic Research 56, 503-510.

Webb WB and Aber WR (1985) Relationships between sleep and retirement-nonretirement status. International Journal of Aging and Human Development 20, 13-19.

Westerlund H, Alexanderson K, Åkerstedt T, Magnusson Hanson L, Theorell T and Kivimäki M (2008) Work-related sleep disturbances and sickness absence in the Swedish working population, 1993-1999. Sleep 31, 1169-1177.

Williams SJ (2003) Dormant/mortal bodies: sleep, death and dying in late postmodernity. In Williams SJ (ed.), Medicine and the Body. London: Sage, pp. 112-138.

Cite this article: van de Straat V, Platts LG, Vahtera J, Westerlund H, Bracke P (2020). Reduction in sleep disturbances at retirement: evidence from the Swedish Longitudinal Occupational Survey of Health. Ageing \& Society 40, 2155-2173. https://doi.org/10.1017/S0144686X19000515 